\title{
The Pharmacological Effect of Omega-3 Fatty Acids Prevent Cancer Progression in Colon and Breast Cancer
}

\author{
Kao $\mathrm{CL}^{1 \#}$, Hung YC $\mathrm{Y}^{2 \#}$ and Liu $\mathrm{CM}^{1 *}$ \\ ${ }^{1}$ Department of Nursing, Tzu Hui Institute of Technology, \\ Taiwan \\ ${ }^{2}$ Department of Pharmacy, Kaohsiung Veterans General \\ Hospital, Taiwan. \\ \#These authors contributed equally to this work \\ *Corresponding author: Liu CM, Department of \\ Nursing, Tzu Hui Institute of Technology, Pingtung \\ County 92641, Taiwan
}

Received: November 21, 2017; Accepted: December 12, 2017; Published: December 19, 2017

\section{Introduction}

Essential polyunsaturated fatty acids (PUFAs) is important bio compounds in maintaining on normal or cancer cell functions [1]. Omega-3 polyunsaturated fatty acid (n-3 PUFA) and Omega-6 polyunsaturated fatty acid (n-6 PUFA) are associated with several diseases [2]. Linoleic acid is n-6 PUFA and it can be converted to arachidonic acid. Arachidonic acid is a polyunsaturated fatty acid and it is present in the phospholipids. The arachidonic acid is metabolized by phospholipase A2 (PLA2) involved in the regulation of inflammatory [3]. n-3 PUFA is beneficial to human health. However, n-3 PUFA cannot be synthesized in human body. Foods high in omega-3 polyunsaturated fatty acid include fish, vegetable oils and nuts. The three main n-3 PUFAs are eicosapentaenoic acid (EPA), docosahexaenoic acid (DHA) and alpha-linolenic acid (ALA). A lot of in vitro and in vivo studies have shown that n-6 PUFA induce tumorigenesis [4-6]. Much evidence has shown that n-3 PUFA may be critical to preventing cardiovascular diseases, diabetes and cancers because of antioxidation and anti-inflammatory activities. High n-6 PUFA consumption is associated with the development of cancers and diseases $[2,5,7]$. Therefore, the consumption of $n-3$ PUFAs is positive impact of preventing disease. A lot of studies have shown that high omega-3-PUFA to n-6 PUFA is a strategy to prevent diseases. The current western diet is very high in n-6 PUFA and the ratio of n-6 PUFA / n-3 PUFA has risen to up to 20-30:1, pro-inflammatory and pro-thrombotic eicosanoids generated from omega- 6 fatty acids are produced in larger quantities than those derived from omega-3 fatty acids [8].

EPA and DHA are rich in fish oil. Many studies have shown that EPA or DHA enhance the immune response and induce apoptosis in cancer cells. Due to special biological properties, n-3 PUFA has minimal negative effects in normal cells. Previous studies have indicated the role of fish and marine n-3 fatty acids in cancer prevention. In this review, we will discuss the pharmacological activities of EPA and DHA in breast and colon cancer.

\section{Colon cancer}

Carcinoma of the colon or rectum (or colorectal cancer, CRC) is the second leading cause of cancer-related deaths in the United States and the third most common cancer in men and in women [9]. The risk of developing CRC is influenced by both environmental and genetic factors. Lifestyle is major risk factors that may contribute to an increased risk of colorectal cancer including lack of regular physical activity, a diet low in fruit and vegetables, a low-fiber and high-fat diet, or overweight and obesity. Other risk factors include inflammatory bowel disease such as Crohn's disease or ulcerative colitis. Fish oil in diet may lower risk of death from CRC.

\section{Anti-inflammatory and effects of n-3 PUFAs in colon cancer}

A chronic systemic inflammatory response is clearly implicated in the progressive nutritional and functional decline in the cancer patients and their subsequent poor outcome [10]. Many chronic diseases including cardiovascular disease, diabetes, cancer, obesity, autoimmune diseases, rheumatoid arthritis, asthma and depression are associated with increased production of inflammatory mediators including thromboxane A2 (TXA2), leukotriene B4 (LTB4), IL-1, IL-6, tumor necrosis factor (TNF), and c-reactive protein $[4,11,12]$. Studies have shown that cancer development is associated with over expression of cyclooxygenase (COX) and lipoxygenase (LOX) [13]. n-3 PUFAs seem to act as anti-tumor promoters in CRC carcinogenesis, like non-steroidal anti-inflammatory drugs (NSAIDs).n-3 PUFAs (mainly EPA and DHA) may play competitive roles, including apoptosis, against respective properties as n-6 family 


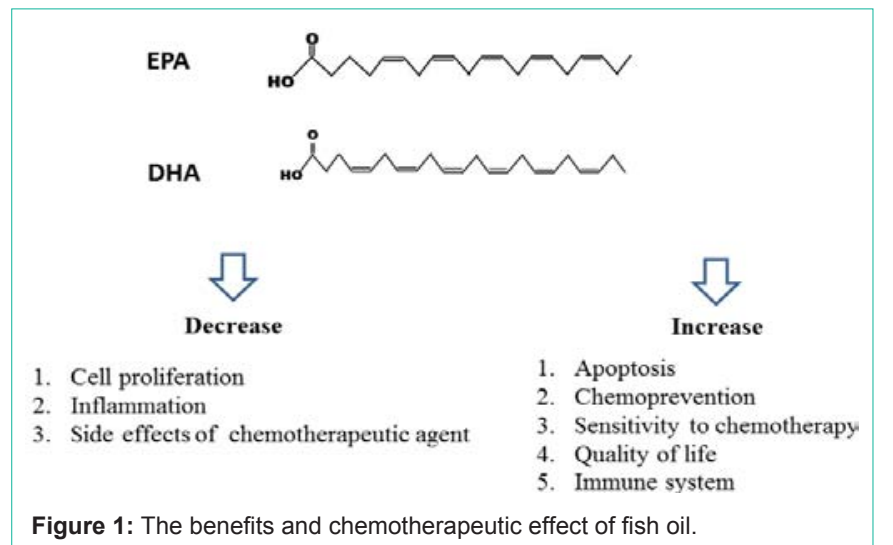

pharmacologic chemicals in LOX and COX pathways [14-17]. In a population study, the serum levels of IL-6, IL-1 and TNF- $\alpha$ were decreased in n-3 PUFAs population. It has suggested that DHA can inhibit colon cancer growth via COX-2 dependent inhibition or COX-2 independent inhibition $[9,16,18,19]$.

The combination therapy is considered as a strategy to enhance the chemotherapy drugs activities. The combination of n-3 PUFAs with chemopreventive phytochemicals are shown in many various experiments [20,21]. In summary, n-3 PUFAs (EPA and DHA) can enhance chemotherapeutic effects and be considered as supportive therapy. n-3 PUFAs inhibit colon cancer growth by modulating redox balance and decreasing inflammatory.

\section{The Effects of $n-3$ PUFAs in breast cancer}

Breast cancer is a leading cause of death in the world. Research has shown that genetic and non-genetic factors may carry an increased risk of developing breast cancer. Non-genetic factors include reproductive factors, body mass index, alcohol intake and physical activity. A number of breast cancer related genes have been identified, including BRCA 1, BRCA 2, ATM, p53, HER2 and PTEN in breast cancer cases [22,23].

Epidermal Growth Factor Receptor (EGFR) and human epidermal growth factor receptor-2 (HER2) are receptor tyrosine kinases. EGFR over expression is associated with cancer progression in breast cancer. A study has shown that DHA can down-regulate EGFR expression and induce apoptosis in breast cancer [24]. BRCA1 and BRCA2 mutations are the cause of most hereditary breast cancer. The risk for developing breast cancer is $80 \%$ with BRCA1 mutations and $60 \%$ with BRCA2 [25]. BRCA1 and BRCA1 proteins are highly involved in ensuring genome stability. BRCA1 is involved in both the checkpoint activation and DNA repair, whereas primarily function of BRCA2 protein is in homologous recombination through its RAD51-binding activity $[25,26]$. The tumor suppressor $\mathrm{p} 53$ has been implicated in many important cellular processes, including DNA repair, cell cycle arrest, senescence, and apoptosis [27,28]. p53 gene mutations were found in $65-80 \%$ of basal or the term triple negative breast cancers [28]. The overall frequency of p53 mutation in breast cancer is approximately 20\% [29]. DHA has also shown to decrease cancer cell growth by increasing BRCA1 transcriptional and protein level [30,31].

Human epidermal growth factor receptor 2 (HER2) is a member of the epidermal growth factor family of receptor tyrosine kinases (ErbBs). HER2 is over expressed in $15-30 \%$ of breast cancer cases [32]. HER2 gene is amplified on 25-50 copies in breast cancers. The ErbBs consists of four members: ErbB1 (EGFR), ErbB2 (HER2, Neu), ErbB3 (HER3) and ErbB4 (HER4) [33]. HER2 can heterodimerise with any of the other ErbB family members and results in the autophosphorylation of tyrosine residues within the cytoplasmic domain of the receptors and initiates a variety of signaling pathways. The phosphorylated HER dimers activate downstream the PI3K/AKT axis and the Raf/MAPK cascade promoting cell growth, proliferation, and survival $[32,34]$. HER2 over expression leads to up regulation of Bcl-2, Bcl-xL, Mcl-1, and suppresses p53-mediated apoptosis by up regulation of MDM2 and activation of AKT [35]. An in vitro study has indicated DHA inhibits HER2 activity and Akt signaling molecules leading to cell death [36].

\section{Conclusion}

EPA and DHA are rich in fish oil. A lot of studies have indicated that EPA and DHA can prevent carcinogenesis and induce cancer cell death in vivo and in vitro study through multiple mechanisms (Figure 1). EPA and DHA can change cellular and molecular level by activating or suppressing signaling pathways, transcription factors and gene expressions. Moreover, EPA and DHA might improve the efficacy of chemotherapeutic agent in many studies through suppression of inflammation or induction of apoptosis. Most studies of EPA and DHA in preventing carcinogenesis are from in vitro or in vivo. In the future, the clinical studies should be conducted.

\section{References}

1. Manzi L, Costantini L, Molinari R, Merendino N. Effect of Dietary omega-3 Polyunsaturated Fatty Acid DHA on Glycolytic Enzymes and Warburg Phenotypes in Cancer. Biomed Res Int. 2015; 137097.

2. Mozaffarian $\mathrm{D}, \mathrm{Wu} \mathrm{JH}$. Omega-3 fatty acids and cardiovascular disease: effects on risk factors, molecular pathways, and clinical events. J Am Coll Cardiol. 2011; 58: 2047-2067.

3. Zaloga GP, Marik P. Lipid modulation and systemic inflammation. Crit Care Clin. 2001; 17: 201-217.

4. Calder PC. Polyunsaturated fatty acids, inflammation, and immunity. Lipids. 2001; 36: 1007-1024.

5. Sibille KT, King C, Garrett TJ, Glover TL, Zhang H, Chen H, et al. Omega-6: Omega-3 PUFA Ratio, Pain, Functioning, and Distress in Adults with Knee Pain. Clin J Pain. 2017 doi: 10.1097/AJP.0000000000000517.

6. Vaidya $\mathrm{H}$, Cheema SK. Breastmilk with a high omega-6 to omega-3 fatty acid ratio induced cellular events similar to insulin resistance and obesity in 3T3L1 adipocytes. Pediatr Obes. 2017 doi: 10.1111/ijpo.12215.

7. Saunders EF, Ramsden CE, Sherazy MS, Gelenberg AJ, Davis JM, Rapoport SI. Omega-3 and Omega-6 Polyunsaturated Fatty Acids in Bipolar Disorder: A Review of Biomarker and Treatment Studies. J Clin Psychiatry. 2016; 77 : e1301-e1308.

8. Lopategi A, Lopez-Vicario C, Alcaraz-Quiles J, Garcia-Alonso V, Rius B, Titos E. Role of bioactive lipid mediators in obese adipose tissue inflammation and endocrine dysfunction. Mol Cell Endocrinol. 2016; 419: 44-59.

9. Viennot S, Deleporte A, Moussata D, Nancey S, Flourie B, Reimund JM Colon cancer in inflammatory bowel disease: recent trends, questions and answers. Gastroenterol Clin Biol. 2009; 33: S190-201.

10. McMillan DC. Systemic inflammation, nutritional status and survival in patients with cancer. Curr Opin Clin Nutr Metab Care. 2009; 12: 223-226.

11. Smith WL, DeWitt DL, Garavito RM. Cyclooxygenases: structural, cellular, 
and molecular biology. Annu Rev Biochem. 2000; 69: 145-182.

12. Sud'ina GF, Pushkareva MA, Shephard P, Klein T. Cyclooxygenase (COX) and 5-lipoxygenase (5-LOX) selectivity of COX inhibitors. Prostaglandins Leukot Essent Fatty Acids. 2008; 78: 99-108

13. Morisseau C, Hammock BD. Impact of soluble epoxide hydrolase and epoxyeicosanoids on human health. Annu Rev Pharmacol Toxicol. 2013; 53: 37-58.

14. Chene G, Dubourdeau M, Balard P, Escoubet-Lozach L, Orfila C, Berry A et al. n-3 and n- 6 polyunsaturated fatty acids induce the expression of COX2 via PPARgamma activation in human keratinocyte HaCaT cells.Biochim Biophys Acta. 2007; 1771: 576-589.

15. Das UN. COX-2 inhibitors and metabolism of essential fatty acids. Med Sc Monit. 2005; 11: RA233-RA237.

16. Owczarek K, Lewandowska U. The Impact of Dietary Polyphenols on COX-2 Expression in Colorectal Cancer. Nutr Cancer. 2017: 1-14.

17. Ringbom T, Huss U, Stenholm A, Flock S, Skattebol L, Perera P, et al. Cox-2 inhibitory effects of naturally occurring and modified fatty acids. J Nat Prod. 2001; 64: 745-749

18. Zhang $\mathrm{C}, \mathrm{Yu} \mathrm{H}$, Ni X, Shen S, Das UN. Growth inhibitory effect of polyunsaturated fatty acids (PUFAs) on colon cancer cells via their growth inhibitory metabolites and fatty acid composition changes. PloS one. 2015; 10: e0123256.

19. Kuppusamy P, Yusoff MM, Maniam GP, Ichwan SJ, Soundharrajan I, Govindan N. Nutraceuticals as potential therapeutic agents for colon cancer: a review. Acta Pharm Sin B. 2014; 4: 173-181.

20. Tsuda H, Ohshima Y, Nomoto H, Fujita K, Matsuda E, ligo M. Cance prevention by natural compounds. Drug Metab Pharmacokinet. 2004; 19: 245-263.

21. Nishino $H$, Murakoshi M, Mou XY, Wada S, Masuda M, Ohsaka $Y$, et al. Cancer prevention by phytochemicals. Oncology 2005; 69: 38-40.

22. D'Abreo N, Hindenburg AA.Sex hormone receptors in breast cancer. Vitam Horm. 2013; 93: 99-133.

23. Yue W, Wang JP, Li Y, Fan P, Liu G, Zhang N, et al. Effects of estrogen on breast cancer development: Role of estrogen receptor independent mechanisms. Int J Cancer. 2010; 127: 1748-1757.

24. Rogers KR, Kikawa KD, Mouradian M, Hernandez K, McKinnon KM, Ahwah $\mathrm{SM}$, et al. Docosahexaenoic acid alters epidermal growth factor receptor- related signaling by disrupting its lipid raft association. Carcinogenesis. 2010; 31: 1523-1530.

25. Moynahan ME, Pierce AJ, Jasin M. BRCA2 is required for homology-directed repair of chromosomal breaks. Mol Cell. 2001; 7: 263-272.

26. Schlacher K, Christ N, Siaud N, Egashira A, Wu H, Jasin M. Double-strand break repair-independent role for BRCA2 in blocking stalled replication fork degradation by MRE11. Cell. 2011; 145: 529-542.

27. Aylon Y, Oren M. New plays in the p53 theater. Curr Opin Genet Dev. 2011 21: 86-92.

28. Synnott NC, Murray A, McGowan PM, Kiely M, Kiely PA, O'Donovan N, et al Mutant p53: a novel target for the treatment of patients with triple-negative breast cancer? Int J Cancer. 2017; 140: 234-246.

29. Pharoah PD, Day NE, Caldas C. Somatic mutations in the p53 gene and prognosis in breast cancer: a meta-analysis. Br J Cancer. 1999; 80: 19681973.

30. Kachhap SK, Dange PP, Santani RH, Sawant SS, Ghosh SN. Effect of omega-3 fatty acid (docosahexanoic acid) on BRCA1 gene expression and growth in MCF-7 cell line. Cancer Biother Radiopharm. 2001; 16: 257-263.

31. Jourdan ML, Maheo K, Barascu A, Goupille C, De Latour MP,Bougnoux $\mathrm{P}$, et al. Increased BRCA1 protein in mammary tumours of rats fed marine omega-3 fatty acids. Oncol Rep. 2007; 17: 713-719.

32. Iqbal N, Iqbal N. Human Epidermal Growth Factor Receptor 2 (HER2) in Cancers: Overexpression and Therapeutic Implications. Mol Biol Int. 2014; 2014: 852748.

33. Kallioniemi OP, Kallioniemi A, Kurisu W, Thor A, Chen LC, Smith HS, et al. ERBB2 amplification in breast cancer analyzed by fluorescence in situ hybridization. Proc Natl Acad Sci USA. 1992; 89: 5321-5325.

34. Yan M, Parker BA, Schwab R, Kurzrock R. HER2 aberrations in cancer implications for therapy. Cancer Treat Rev. 2014; 40: 770-780.

35. Carpenter RL, Lo HW. Regulation of Apoptosis by HER2 in Breast Cancer. J Carcinog Mutagen. 2013; 2013(Suppl 7): 003.

36. Ravacci GR, Brentani MM, Tortelli TC, Torrinhas RS, Santos JR, Logullo AF. Docosahexaenoic Acid Modulates a HER2-Associated Lipogenic Phenotype, Induces Apoptosis, and Increases Trastuzumab Action in HER2Overexpressing Breast Carcinoma Cells. Biomed Res Int. 2015; 2015: 838652.
Austin J Nutri Food Sci - Volume 5 Issue 2 - 2017

ISSN : 2381-8980 | www.austinpublishing group.com

Liv et al. (C) All rights are reserved
Citation: Kao CL, Hung YC and Liu CM. The Pharmacological Effect of Omega-3 Fatty Acids Prevent Cancer Progression in Colon and Breast Cancer. Austin J Nutri Food Sci. 2017; 5(2): 1090. 